\title{
Effects of compound probiotics on growth performance, rumen fermentation, blood parameters, and health status of neonatal Holstein calves
}

\author{
Haibo Wang, ${ }^{1,2 *} \odot$ Zhaotao Yu, ${ }^{1,3 *}$ Zhibiao Gao, ${ }^{1}$ Qianwen Li, ${ }^{1}$ Xinjun Qiu, ${ }^{1}$ Fei Wu, ${ }^{1}$ Tianci Guan, ${ }^{1}$ \\ Binghai Cao, ${ }^{1}$ and Huawei $\mathrm{Su}^{1}+$ (i) \\ ${ }^{1}$ State Key Laboratory of Animal Nutrition, College of Animal Science and Technology, China Agricultural University, Beijing 100193, China \\ ${ }^{2}$ Key Laboratory of Qinghai-Tibetan Plateau Animal Genetic Resource Reservation and Utilization, Southwest Minzu University, \\ Ministry of Education, Chengdu 610000, China \\ ${ }^{3}$ Department of Animal Science, University of Tennessee, Knoxville 37996
}

\section{ABSTRACT}

This study aimed to investigate the effects of compound probiotics (consisting of $10^{8} \mathrm{cfu} / \mathrm{g}$ of Lactobacillus plantarum, $10^{8} \mathrm{cfu} / \mathrm{g}$ of Pediococcus acidilactici, $10^{8} \mathrm{cfu} / \mathrm{g}$ of Pediococcus pentosaceus, $10^{7} \mathrm{cfu} / \mathrm{g}$ of and Bacillus subtilis) on growth performance, rumen fermentation, bacteria community, blood parameters, and health status of Holstein calves at the first 3 mo of age. Forty-eight newborn calves were randomly divided into the following 3 groups: control group (milk replacer with no compound probiotics), low compound probiotics group (milk replacer $+0.12 \mathrm{~g}$ of compound probiotics per head per day), and high compound probiotics group (HP; milk replacer $+1.2 \mathrm{~g}$ of compound probiotics per head per day). Starter pellets of the low compound probiotics and HP groups were coated with $0.05 \%$ compound probiotics. Milk replacer was provided from 2 to $63 \mathrm{~d}$ of age $(6 \mathrm{~L}$ at $2-10 \mathrm{~d}, 8 \mathrm{~L}$ at $11-42 \mathrm{~d}, 6$ $\mathrm{L}$ at $43-49 \mathrm{~d}, 4 \mathrm{~L}$ at $50-56 \mathrm{~d}$, and $2 \mathrm{~L}$ at $57-63 \mathrm{~d}$ ), and starter pellets were provided ad libitum from 7 to 90 $\mathrm{d}$ of age. Body weight and body size (d 1, 30, 60, and 90), blood (d 40 and 80), and rumen fluid (d 90) were analyzed using the one-way ANOVA procedure; fecal score was recorded daily and analyzed as repeated measures using the mixed model procedure. Results showed that diet supplemented with compound probiotics had no effects on the body weight, average daily gain, dry matter intake, and feed efficiency. At $90 \mathrm{~d}$ of age, diet supplemented with compound probiotics decreased the withers height. Immunity activities increased in the HP group, supported by the increased concentrations of serum total protein and immunoglobulins at $40 \mathrm{~d}$ of age, and by the increased activity of superoxide dismutase

Received May 10, 2021.

Accepted November 6, 2021.

*These authors contributed equally to this work.

†Corresponding author: suhuawei@cau.edu.cn at $80 \mathrm{~d}$ of age. Diet supplemented with compound probiotics altered rumen fermentation, indicated by the decreased rumen acetic acid and propionic acid, and the increased butyric acid concentrations. Diet supplemented with compound probiotics improved the health status of calves, indicated by the decreased fecal score at $3 \mathrm{wk}$ of age and the decreased medicine treatments. In summary, although diet supplemented with HP decreased the withers height, this level of probiotics is recommended to improve rumen development and health status of newborn Holstein calves.

Key words: Holstein calf, compound probiotic, growth performance, rumen fermentation, health status

\section{INTRODUCTION}

Newborn calves are sensitive to environmental changes and colonization by opportunistic and potentially pathogenic bacteria, which may lead to their high morbidity and mortality (Alawneh et al., 2020; Osorio, 2020). Diarrhea and respiratory disease are the 2 primary causes of early calf morbidity and mortality (Malmuthuge et al., 2015). Acute diarrhea is the primary issue for the first 3 wk of life; this is replaced by respiratory disease by around $4 \mathrm{wk}$ of age. Morbidity rates due to neonatal diarrhea can be as high as $21 \%$ in individual herds, and mortality rates can be as high as 5 to $8 \%$ (Meganck et al., 2015). Therefore, it is imperative to implement strategies to reduce the diarrhea in the early life of a calf.

Just as in humans, the discovery that an animal harbors a complex microbiota inside the digestive tract invariably led to the belief that this ecosystem can be modified to promote or even restore health (O'Hara et al., 2020). Understanding the principles that regulate short and long-term microbial colonization inside the digestive tract is essential to the success of microbiomebased therapies using beneficial microorganisms (Walter et al., 2018), especially in livestock operations. Antimicrobials and probiotics were usually used to modulate 
the microorganisms in the gastrointestinal tract. One approach is killing the pathogenic microorganism by administrating antimicrobials; however, this approach is not common practice due to the negative effect of antimicrobials on the beneficial gastrointestinal tract microbiota, and the presence of violative levels of antimicrobial residues in dairy and meat products (Tang et al., 2017). Another approach is to use live microorganisms, known as probiotics, that confer a benefit to the host when administered in adequate amounts (Hill et al., 2014; Garcia-Mazcorro et al., 2020). Thus, probiotics are extensively used as feed additives due to the potential positive effect of establishing a protective microflora in the gastrointestinal tract of calves.

Health risks before weaning are very high as calves remain highly susceptible to disease and environmental stress during this period (Hammon et al., 2020). An early feeding regimen and nutrition have effects on rumen development and the establishment of rumen microbiota. This effect could persist for a long time and, consequently, affect the lifetime productive performance and health of adult ruminants (Soberon et al., 2012; Soberon and Van Amburgh, 2013). Lactic acid bacteria have been identified as a tool to maintain the intestinal microbial balance and to prevent the establishment of opportunistic pathogenic bacterial populations (Signorini et al., 2012). Additionally, Bacillus species are believed to reduce pathogen colonization by activating key survival pathways and stimulating the immune system in epithelial cells (Williams, 2007; Piewngam et al., 2018). However, the effects of probiotics on the growth and health of calves are inconclusive and frequently driven by differences in probiotics species, viable probiotic bacterial numbers, and administration methods (Diao et al., 2019). Administration of an inoculum formed by a mixture of different strains may be an effective way to achieve a relative stable effect to calves. Therefore, we added a commercial compound probiotics product, including 3 lactic acid bacteria and Bacillus subtilis in the diets, and hypothesized that a compound probiotic could play a vital role in the growth and health of calves.

\section{MATERIALS AND METHODS}

\section{Treatments, Animals, and Feeding}

This experiment was conducted at Modern Farming (Bengbu, China). The protocols were approved by the Laboratory Animal Welfare and Animal Experimental Ethical Committee of China Agricultural University (permit no. AW21109102-2). Forty-eight male newborn Holstein calves $(41.3 \pm 3.89 \mathrm{~kg}, \mathrm{SD})$ were randomly se- lected from 165 newborn calves. These calves received 4 L of colostrum (IgG $>50 \mathrm{mg} / \mathrm{mL}$ ) via esophageal tube within $2 \mathrm{~h}$ after birth, and subsequently another $2 \mathrm{~L}$ colostrum was fed after $12 \mathrm{~h}$. Calves were put in a box and weighed within $2 \mathrm{~h}$ after birth, and the calves were randomly assigned to 1 of 3 groups according to BW. The BW were sequenced from light to heavy, and then the randomization sequence was produced using Excel (Microsoft 365), with each group containing 16 replicates as follows: control group $(\mathbf{C O N}$; milk replacer with no compound probiotics), low compound probiotics group (LP; milk replacer $+0.12 \mathrm{~g}$ of compound probiotics per head per day), and high compound probiotics group (HP; milk replacer $+1.2 \mathrm{~g}$ of compound probiotics per head per day). In addition, starter pellets of the LP and HP groups were coated with $0.05 \%$ compound probiotics. The compound probiotics used in this were BioWiSH MultiBio 3PS (BiOWiSH Technologies Inc.), which contained $10^{8} \mathrm{cfu} / \mathrm{g}$ of Lactobacillus plantarum, $10^{8} \mathrm{cfu} / \mathrm{g}$ of Pediococcus acidilactici, $10^{8}$ $\mathrm{cfu} / \mathrm{g}$ of Pediococcus pentosaceus, and $10^{7} \mathrm{cfu} / \mathrm{g}$ of $\mathrm{Ba}$ cillus subtilis. The milk replacers were provided twice daily at 0700 and $1700 \mathrm{~h}$. The milk replacer was dissolved with hot water $\left(50-60^{\circ} \mathrm{C}\right)$ to $14.3 \%$ solids and fed when the temperature reached approximately $40^{\circ} \mathrm{C}$. The milk replacer amount was provided as follows: 6 L $(2-10 \mathrm{~d}), 8 \mathrm{~L}(11-42 \mathrm{~d}), 6 \mathrm{~L}(43-49 \mathrm{~d})$, and $4 \mathrm{~L}$ (50-56 d). At 57 to $63 \mathrm{~d}$ of age, the milk replacer was provided once daily at the amount of $2 \mathrm{~L}$. Clean water was provided ad libitum after $1 \mathrm{~h}$ of milk feeding. The starter pellets (Shanghai Holstein Technology Co. Ltd.) were provided ad libitum from 7 to $90 \mathrm{~d}$ of age, and the ingredients and nutrient composition of starter pellets are presented in Table 1. All calves were housed individually in calf hutches and enrolled in the experiment over 3 mo.

\section{Sampling and Laboratory Analyses}

At 1, 30, 60, and $90 \mathrm{~d}$ of age, calves were weighed with a digital scale, and the body sizes (including withers height, hip height, body length, and heart girth) were measured according to the method described by Wilson et al. (1997) by the same person throughout the experiment. The milk replacer and starter pellet intake was recorded daily. The starter pellets were collected monthly and dried at $65^{\circ} \mathrm{C}$ for $48 \mathrm{~h}$ in the oven, then ground through a 1-mm screen (Wiley, A. H. Thomas Co.) for analyzing DM, CP, and ether extract following the AOAC method (AOAC, 1990). The contents of $\mathrm{CP}$ and ether extract were analyzed using the Kjeldahl nitrogen determination apparatus (Kjeltec 2100, Foss) and the AnkomXT15 Extractor (Ankom Technology), 
Table 1. Ingredient and nutrient composition of calf starter pellets

\begin{tabular}{lccc}
\hline & \multicolumn{3}{c}{ Diet $^{1}$} \\
\cline { 2 - 4 } Item & $\mathrm{CON}$ & $\mathrm{LP}$ & $\mathrm{HP}$ \\
\hline Ingredient, \% & & & \\
Corn grain & 34.50 & 34.50 & 34.50 \\
Barley grain & 12.0 & 12.0 & 12.0 \\
Wheat middling & 4.00 & 3.95 & 3.95 \\
Soybean meal & 16.0 & 16.0 & 16.0 \\
Canola meal & 13.0 & 13.0 & 13.0 \\
DDGS $^{2}$ & 16.0 & 16.0 & 16.0 \\
CaHPO $_{4}$ & 0.50 & 0.50 & 0.50 \\
CaCO $_{3}$ & 1.50 & 1.50 & 1.50 \\
NaCl & 1.0 & 1.0 & 1.0 \\
Premix compound & 1.0 & 1.0 & 1.0 \\
Molasses & 0.50 & 0.50 & 0.50 \\
Compound probiotics & - & 0.05 & 0.05 \\
Nutrient composition, $\%$ & & & \\
DM & 91.0 & 90.6 & 90.6 \\
CP & 20.8 & 20.8 & 20.8 \\
Ether extract & 4.47 & 4.29 & 4.29 \\
\hline
\end{tabular}

${ }^{1}$ Diet supplemented with compound probiotics in different levels: CON $=$ control, both milk replacer and starter pellets supplemented with no compound probiotics; LP = low compound probiotics, milk replacer supplemented with $0.12 \mathrm{~g}$ of compound probiotics per head per day, and starter pellets supplemented with $0.05 \%$ compound probiotics; HP $=$ high compound probiotics, milk replacer supplemented with $1.2 \mathrm{~g}$ of compound probiotics, and starter pellets supplemented with $0.05 \%$ compound probiotics.

${ }^{2}$ DDGS $=$ distillers dried grains with solubles.

respectively. Feces were scored daily in the morning by Zhantao $\mathrm{Yu}$, who was trained by the Elite Cattlemen Program and had more than 2 yr working experience, according to the standard of Osorio et al. (2012). Feces were scored as 1 when firm (well formed, not hard), 2 when soft (pudding-like), 3 when runny (pancake batter), and 4 when liquid (splatters); diarrhea was defined when fecal score was 3 and 4 ; and the diarrhea rate was the ratio of the number of diarrhea calves to the number of total calves. Medicine treatment was recorded daily, and medical therapy of $5 \mathrm{~mL}$ of enrofloxacin, 3 $\mathrm{mL}$ of flunixin meglumine injection, $6 \mathrm{~mL}$ of ceftiofur hydrochloride injection, and $6 \mathrm{~mL}$ of ceftiofur hydrochloride injection would be provided to the calf if it had diarrhea, fever, pneumonia, or cough, respectively.

At 40 and $80 \mathrm{~d}$ of age, blood was sampled via the jugular vein into $10-\mathrm{mL}$ evacuated serum tubes before morning feeding, centrifuged at $3,500 \times g$ for $15 \mathrm{~min}$ at $25^{\circ} \mathrm{C}$, and then the serum was collected into $1.5-\mathrm{mL}$ microtubes and stored at $-20^{\circ} \mathrm{C}$ for further analysis. Biochemical indicators were determined using an automated biochemistry analyzer (Hitachi 7020; Hitachi Co.). Glucose, total protein, and immunoglobulin concentrations were determined using commercial test kits (Jiuqiang Bio-Technique Co.) with glucose oxidase (glucose) and biuret (protein and immunoglobulins). Oxidative biomarkers glutathione peroxidase, superox- ide dismutase (SOD), malondialdehyde (MDA), and total antioxidant capacity were analyzed according to kit instructions (Suolaibao Biotechnology Co, Ltd.) using the thiobarbituric acid, xanthine oxidase reaction, hydroxylamine, and calorimetry methods, respectively. Insulin-like growth factor-1 was analyzed using ELISA kits (Suolaibao Biotechnology Co, Ltd.).

At $90 \mathrm{~d}$ of age, rumen fluid was collected at $3 \mathrm{~h}$ after the morning feeding using a flexible esophageal tube (Kelibo Co, Ltd.), which was cleaned thoroughly with fresh water during the samples collection. After discarding the first $50 \mathrm{~mL}$ of rumen fluid to minimize saliva contamination and then collecting about $50 \mathrm{~mL}$ of rumen fluid (both solid and liquid fractions), the $\mathrm{pH}$ of rumen fluid was determined immediately using a handheld electronic $\mathrm{pH}$ meter. After that, rumen fluid was centrifuged at $3,000 \times g$ for $10 \mathrm{~min}$ at $25^{\circ} \mathrm{C}$ to collect the supernatant, then $1 \mathrm{~mL}$ of the supernatant was mixed with $0.25 \mathrm{~mL}$ of metaphosphoric acid standard solution $(25 \mathrm{~g} / 100 \mathrm{~mL})$ for later analysis of VFA and $\mathrm{NH}_{3}-\mathrm{N}$ concentrations. The $\mathrm{NH}_{3}-\mathrm{N}$ of rumen liquid was measured by alkaline phenol hypochlorite method (Weatherburn, 1967) using a spectrophotometer (UV1700, Shimadzu Corporation). The VFA was quantified using a high-performance gas chromatograph (GC2014; Shimadzu Corporation), which was equipped with a hydrogen flame detector and a capillary column (Agilent, Technologies; $30 \mathrm{~m}$ long, 0.32-mm diameter, $0.50-\mu \mathrm{m}$ film thickness).

Quantitative real-time PCR was used to determine the relative abundance of the bacterial populations as follows: Fibrobacter succinogenes, Butyrivibrio fibrisolvens, Streptococcus bovis, Prevotella bryantii, Ruminobacter amylophilus, and total bacteria. The primer sequences to amplify the bacteria are shown in Table 2. About $1.5 \mathrm{~mL}$ of rumen fluid was used for DNA extraction. The DNA were obtained following the instructions of the DNA extraction kit (Omega Bio-Tek). The concentration and purity of DNA were evaluated with a spectrophotometer (UV-1700, Shimadzu Corp.) at 260 and $280 \mathrm{~nm}$. In this study, the concentration of DNA was $50 \mathrm{ng} / \mu \mathrm{L}$ and the ratio of 260 to $280 \mathrm{~nm}$ were between 1.8 and 2.0. The SYBR green fluorescent dye (Agilent Technologies) was selected for real-time fluorescence quantitative test. The abundance of microbes was represented as the proportion of total bacteria according to the following formula (Livak and Schmittgen, 2001): proportion of target $=2^{- \text {(Ct target }-\mathrm{Ct} \text { total bacteria })}$, where Ct represents the threshold cycle.

\section{Statistical Analysis}

Data were analyzed as a randomized complete block design. Dependent variables (DMI, BW, ADG, feed ef- 
Table 2. Primer of real-time $\mathrm{PCR}^{1}$

\begin{tabular}{lll}
\hline Target & Primer sequence $\left(5^{\prime}\right.$ to $\left.3^{\prime}\right)$ & Reference \\
\hline Total bacteria & F: CGGCAACGAGCGCAACCC & Denman and McSweeney, 2006 \\
Fibrobacter succinogenes & R: CCATTGTAGCACGTGTGTAGCC & Denman and McSweeney, 2006 \\
Streptococcus bovis & R: GTTCGGATTACTGGGCGTAAA & Stevenson and Weimer, 2007 \\
Prevotella bryantii & F: TTCCTAGAGCTGAACTAC & Niu et al., 2018 \\
Ruminobacter amylophilus & R: ATGATGGCAACTAACAATAGGGGT & Niu et al., 2018 \\
Butyrivibrio fibrisolvens & R: GAAGGGGCACGAACTGTCAGA & Stevenson and Weimer, 2007 \\
& F: CTTGCTTCCTGGCTGACG & \\
\hline
\end{tabular}

${ }^{1} \mathrm{~F}=$ forward; $\mathrm{R}=$ reverse.

ficiency, body measurements, blood metabolites, oxidative biomarkers, and rumen microbiome) were analyzed using the one-way ANOVA procedure of SAS (version 9.2, SAS Institute Inc.). The parameter fecal score was analyzed as repeated measures using the mixed model procedure of SAS (version 9.2, SAS Institute Inc.), and a covariate was included in the model when appropriate but was removed from the model when not significant. The statistical model was as follows: $\mathrm{Y}_{i j k}=\mu+\tau_{i}+\beta_{j}$ $+\tau \beta_{i j}+\varepsilon_{i j k}$, where $\mathrm{Y}_{i j k}$ is observation $k$ in treatment $i$ and age $j, \mu$ is the overall mean, $\tau_{i}$ is the effect of compound probiotics level ( $i=1,2$ or 3 ), $\beta_{j}$ is the effect of age $(j=1, \ldots, 7), \tau \beta_{i j}$ is the interaction effect of treatment $i$ and age $j$, and $\varepsilon_{i j k}$ is random error. The fecal scores were measured daily, and time effect was considered the average weekly value. Significance was declared at $P<0.05$ and trends at $P<0.10$.

\section{RESULTS}

\section{Growth Performance}

The initial BW of calves in HP, LP, and CON groups was $41.0 \mathrm{~kg}, 40.9 \mathrm{~kg}$ and $41.8 \mathrm{~kg}$, respectively, and diet supplemented with compound probiotics had no effects on BW at 30,60, and $90 \mathrm{~d}$ of age (Table 3 ). The ADG were similar among groups; calves in the HP group had numerically higher ADG than those in other groups throughout the experiment. Diet supplemented with compound probiotics had no effects on the DMI and feed efficiency during the experiment periods $(P$ $>0.05)$.

Effects of compound probiotics on body size are shown in Table 4. At $90 \mathrm{~d}$ of age, diet supplemented with compound probiotics decreased the withers height $(P=0.035)$. No significant differences were observed among the groups for heart girth during the experiment period $(P>0.05)$.

\section{Blood Metabolites and Oxidative Biomarkers}

The effects of compound probiotics on the blood parameters of calves are shown in Table 5. Diet supplement with compound probiotics had no effects on the

Table 3. Effects of compound probiotics on growth performance and feed intake of Holstein calves

\begin{tabular}{|c|c|c|c|c|c|}
\hline \multirow[b]{2}{*}{ Item } & \multicolumn{3}{|c|}{ Diet $^{1}$} & \multirow[b]{2}{*}{ SEM } & \multirow[b]{2}{*}{$P$-value } \\
\hline & $\mathrm{CON}$ & LP & HP & & \\
\hline \multicolumn{6}{|l|}{$\mathrm{BW}, \mathrm{kg}$} \\
\hline $1 \mathrm{~d}$ & 41.9 & 40.9 & 41.0 & 0.562 & 0.756 \\
\hline $30 \mathrm{~d}$ & 59.9 & 57.8 & 59.6 & 0.769 & 0.551 \\
\hline $60 \mathrm{~d}$ & 80.9 & 78.5 & 81.5 & 1.189 & 0.491 \\
\hline $90 \mathrm{~d}$ & 114.6 & 111.2 & 114.6 & 1.672 & 0.582 \\
\hline \multicolumn{6}{|l|}{$\mathrm{DMI},{ }^{2} \mathrm{~kg}$} \\
\hline $1-30 \mathrm{~d}$ & 0.88 & 0.86 & 0.90 & 0.010 & 0.155 \\
\hline $30-60 \mathrm{~d}$ & 1.16 & 1.13 & 1.16 & 0.031 & 0.920 \\
\hline $60-90 \mathrm{~d}$ & 2.64 & 2.60 & 2.78 & 0.058 & 0.441 \\
\hline $1-60 \mathrm{~d}$ & 1.01 & 0.98 & 1.02 & 0.017 & 0.697 \\
\hline $1-90 \mathrm{~d}$ & 1.62 & 1.58 & 1.67 & 0.030 & 0.514 \\
\hline \multicolumn{6}{|c|}{$\mathrm{ADG}, \mathrm{kg} / \mathrm{d}$} \\
\hline $1-30 \mathrm{~d}$ & 0.60 & 0.59 & 0.66 & 0.020 & 0.367 \\
\hline $30-60 \mathrm{~d}$ & 0.70 & 0.70 & 0.75 & 0.027 & 0.737 \\
\hline $60-90 \mathrm{~d}$ & 1.13 & 1.08 & 1.16 & 0.024 & 0.426 \\
\hline $1-60 \mathrm{~d}$ & 0.65 & 0.65 & 0.71 & 0.020 & 0.359 \\
\hline $1-90 \mathrm{~d}$ & 0.81 & 0.79 & 0.86 & 0.018 & 0.293 \\
\hline \multicolumn{6}{|l|}{$\mathrm{FE}^{3}$} \\
\hline $1-30 \mathrm{~d}$ & 1.59 & 1.55 & 1.41 & 0.060 & 0.435 \\
\hline $30-60 \mathrm{~d}$ & 1.67 & 1.71 & 1.64 & 0.035 & 0.680 \\
\hline $60-90 \mathrm{~d}$ & 2.33 & 2.44 & 2.39 & 0.038 & 0.514 \\
\hline $1-60 \mathrm{~d}$ & 1.59 & 1.59 & 1.48 & 0.029 & 0.234 \\
\hline $1-90 \mathrm{~d}$ & 1.98 & 2.02 & 1.95 & 0.018 & 0.282 \\
\hline
\end{tabular}

${ }^{1}$ Diet supplemented with compound probiotics in different levels: CON $=$ control, both milk replacer and starter pellets supplemented with no compound probiotics; LP = low compound probiotics, milk replacer supplemented with $0.12 \mathrm{~g}$ of compound probiotics per head per day, and starter pellets supplemented with $0.05 \%$ compound probiotics; HP $=$ high compound probiotics, milk replacer supplemented with $1.2 \mathrm{~g}$ of compound probiotics, and starter pellets supplemented with $0.05 \%$ compound probiotics.

${ }^{2} \mathrm{DMI}=$ total $\mathrm{DM}$ of feed, including milk replacer and starter pellets.

${ }^{3} \mathrm{FE}=$ feed efficiency, the ratio of DMI to ADG. 
concentrations of serum glucose, MDA, and IGF-I, and the activity of total antioxidant capacity $(P>0.05)$. At $40 \mathrm{~d}$ of age, the concentrations of serum total protein of calves in the HP group were higher than those in the CON and LP groups $(P=0.042)$, and calves in the HP group tended to have a higher concentration of immunoglobulins than those in the LP group $(P=0.098)$. At $80 \mathrm{~d}$ of age, calves in the HP group had higher activity of SOD than those in the LP group $(P=0.023)$. In terms of age, the concentrations of serum glucose and total protein increased, whereas the concentrations of serum MDA decreased with the growth of calves.

\section{Rumen Fermentation and Selected Rumen Bacterial Abundance}

Effects of diet supplemented with compound probiotics on rumen fermentation are shown in Table 6 . Ruminal $\mathrm{pH}$ and $\mathrm{NH}_{3}-\mathrm{N}$ concentrations were similar among the groups $(P>0.05)$. There were significant differences in acetic acid $(P=0.006)$ and propionic acid $(P=0.003)$ concentrations among the groups; the concentrations of acetic acid and propionic acid in the CON group were significantly higher than those in the LP and HP groups. The concentrations of butyric acid in the CON group were significantly lower than those in the LP and HP groups $(P=0.016)$. No significant differences in the concentrations of isobutyric acid, isovaleric acid, valeric acid, and total VFA were found. The ratios of acetic acid to propionic acid were detected among the groups $(P>0.05)$.

There was no difference in the abundances of the selected rumen bacteria among the groups $(P>0.05)$ (Table 7). The relative abundances of Fibrobacter succinogenes, Butyrivibrio fibrisolvens, Streptococcus bovis, Prevotella bryantii, and Ruminobacter amylophilus were between $0.5 \%$ and $0.8 \%, 1.5 \%$ and $2.5 \%, 2 \%$ and $3.5 \%$, $2 \%$ and $4 \%$, and $0.1 \%$ and $0.7 \%$, respectively.

\section{Fecal Score and Medicine Treatment}

The influence of diet supplemented with compound probiotics on calf fecal score and medicine treatment are shown in Table 8. In this experiment, the diarrhea rate overall for the first 4 wk was $5.95 \%$, and at 1 to 4 wk of age were $2.38 \%, 17.26 \%, 4.17 \%$ and $0 \%$, respectively. No significant differences in fecal score were detected among the treatments at 1,2 and $4 \mathrm{wk}$ of age $(P>0.05)$, whereas calves in the CON group had a higher fecal score than those in the LP and HP groups at 3 wk of age $(P=0.004)$. At 3 wk of age, the diarrhea rate in $\mathrm{CON}, \mathrm{HP}$, and LP groups were $10.71 \%, 0.89 \%$ and $0.89 \%$, respectively. The fecal score was affected by the age of calves during the first $4 \mathrm{wk}$ $(P<0.001)$, and there had an interaction between the diet and date at the first $4 \mathrm{wk}(P=0.005)$. Medicine treatments of the CON, LP, and HP groups were 13, 4, and 5 , respectively; compared with the $\mathrm{CON}$ group, the

Table 4. Effects of compound probiotics on body size of Holstein calves

\begin{tabular}{|c|c|c|c|c|c|}
\hline \multirow[b]{2}{*}{ Item } & \multicolumn{3}{|c|}{ Diet $^{1}$} & \multirow[b]{2}{*}{ SEM } & \multirow[b]{2}{*}{$P$-value } \\
\hline & $\mathrm{CON}$ & LP & HP & & \\
\hline \multicolumn{6}{|c|}{ Withers height, cm } \\
\hline $30 \mathrm{~d}$ & $78.3^{\mathrm{b}}$ & $79.1^{\mathrm{ab}}$ & $80.7^{\mathrm{a}}$ & 0.459 & 0.098 \\
\hline $60 \mathrm{~d}$ & 85.2 & 84.9 & 86.4 & 0.413 & 0.322 \\
\hline $90 \mathrm{~d}$ & $93.6^{\mathrm{a}}$ & $91.5^{\mathrm{b}}$ & $91.6^{\mathrm{b}}$ & 0.387 & 0.035 \\
\hline \multicolumn{6}{|c|}{ Hip height, cm } \\
\hline $30 \mathrm{~d}$ & 85.7 & 85.4 & 85.0 & 0.403 & 0.792 \\
\hline $60 \mathrm{~d}$ & 92.7 & 92.3 & 93.3 & 0.460 & 0.678 \\
\hline $90 \mathrm{~d}$ & $98.5^{\mathrm{a}}$ & $96.1^{\mathrm{b}}$ & $96.6^{\mathrm{ab}}$ & 0.449 & 0.068 \\
\hline \multicolumn{6}{|c|}{ Body length, cm } \\
\hline $30 \mathrm{~d}$ & 85.9 & 84.7 & 85.6 & 0.433 & 0.508 \\
\hline $60 \mathrm{~d}$ & 97.3 & 93.1 & 94.4 & 0.823 & 0.103 \\
\hline $90 \mathrm{~d}$ & $105.1^{\mathrm{a}}$ & $102.7^{\mathrm{ab}}$ & $102.3^{\mathrm{b}}$ & 0.554 & 0.071 \\
\hline \multicolumn{6}{|c|}{ Heart girth, cm } \\
\hline $30 \mathrm{~d}$ & 95.4 & 94.1 & 95.1 & 0.550 & 0.606 \\
\hline $60 \mathrm{~d}$ & 105.0 & 104.1 & 106.4 & 0.610 & 0.283 \\
\hline $90 \mathrm{~d}$ & 115.0 & 114.3 & 115.4 & 0.533 & 0.690 \\
\hline
\end{tabular}

${ }^{\mathrm{a}, \mathrm{b}}$ Mean values in the same row with different superscripts differ $(P<0.05)$.

${ }^{1}$ Diet supplemented with compound probiotics in different levels: $\mathrm{CON}=$ control, both milk replacer and starter pellets supplemented with no compound probiotics; LP = low compound probiotics, milk replacer supplemented with $0.12 \mathrm{~g}$ of compound probiotics per head per day, and starter pellets supplemented with $0.05 \%$ compound probiotics; HP = high compound probiotics, milk replacer supplemented with $1.2 \mathrm{~g}$ of compound probiotics, and starter pellets supplemented with $0.05 \%$ compound probiotics. 
Table 5. Effects of compound probiotics on blood parameters of Holstein calves

\begin{tabular}{|c|c|c|c|c|c|}
\hline \multirow[b]{2}{*}{ Item } & \multicolumn{3}{|c|}{ Diet $^{1}$} & \multirow[b]{2}{*}{ SEM } & \multirow[b]{2}{*}{$P$-value } \\
\hline & $\mathrm{CON}$ & LP & HP & & \\
\hline \multicolumn{6}{|c|}{ Glucose, mmol/L } \\
\hline $40 \mathrm{~d}$ & 4.10 & 3.74 & 4.28 & 0.139 & 0.272 \\
\hline $80 \mathrm{~d}$ & 5.15 & 5.26 & 5.22 & 0.106 & 0.918 \\
\hline \multicolumn{6}{|c|}{ Total protein, $\mathrm{g} / \mathrm{L}$} \\
\hline $40 \mathrm{~d}$ & $44.5^{\mathrm{b}}$ & $44.0^{\mathrm{b}}$ & $50.3^{\mathrm{a}}$ & 1.176 & 0.042 \\
\hline $80 \mathrm{~d}$ & 51.8 & 53.7 & 53.3 & 0.837 & 0.661 \\
\hline \multicolumn{6}{|c|}{ Immunoglobulin, g/dL } \\
\hline $40 \mathrm{~d}$ & $256.6^{\mathrm{ab}}$ & $238.4^{\mathrm{b}}$ & $292.2^{\mathrm{a}}$ & 10.46 & 0.098 \\
\hline $80 \mathrm{~d}$ & 270.4 & 277.4 & 293.4 & 11.96 & 0.740 \\
\hline \multicolumn{6}{|c|}{ IGF-I, ng/mL } \\
\hline $40 \mathrm{~d}$ & 36.6 & 32.2 & 37.2 & 2.01 & 0.546 \\
\hline $80 \mathrm{~d}$ & 40.2 & 39.9 & 50.1 & 2.22 & 0.100 \\
\hline \multicolumn{6}{|c|}{ Malondialdehyde, nmol/L } \\
\hline $40 \mathrm{~d}$ & 2.30 & 2.11 & 2.13 & 0.291 & 0.962 \\
\hline $80 \mathrm{~d}$ & 0.25 & 0.43 & 0.40 & 0.053 & 0.353 \\
\hline \multicolumn{6}{|c|}{ Superoxide dismutase, $\mathrm{U} / \mathrm{mL}$} \\
\hline $40 \mathrm{~d}$ & 179.8 & 161.6 & 182.0 & 6.14 & 0.342 \\
\hline $80 \mathrm{~d}$ & $184.9^{\mathrm{ab}}$ & $161.2^{\mathrm{b}}$ & $212.4^{\mathrm{a}}$ & 7.88 & 0.023 \\
\hline \multicolumn{6}{|c|}{$\mathrm{TAOC}^{2} \mathrm{U} / \mathrm{mL}$} \\
\hline $40 \mathrm{~d}$ & 5.47 & 5.47 & 6.02 & 0.211 & 0.493 \\
\hline $80 \mathrm{~d}$ & 4.67 & 5.02 & 5.01 & 0.191 & 0.723 \\
\hline
\end{tabular}

${ }_{\mathrm{a}, \mathrm{b}}$ Mean values in the same row with different superscripts differ $(P<0.05)$.

${ }^{1}$ Diet supplemented with compound probiotics in different levels: $\mathrm{CON}=$ control, both milk replacer and starter pellets supplemented with no compound probiotics; LP = low compound probiotics, milk replacer supplemented with $0.12 \mathrm{~g}$ of compound probiotics per head per day, and starter pellets supplemented with $0.05 \%$ compound probiotics; $\mathrm{HP}=$ high compound probiotics, milk replacer supplemented with $1.2 \mathrm{~g}$ of compound probiotics, and starter pellets supplemented with $0.05 \%$ compound probiotics.

${ }^{2} \mathrm{TAOC}=$ total antioxidant capacity.

medicine treatments of LP and HP groups decreased $69.2 \%$ and $64.5 \%$, respectively.

\section{DISCUSSION}

Newborn calves have high rates of morbidity and mortality; therefore, it is imperative to implement strategies to ensure the healthy state and nutritional level of calves in the early life stage. Probiotics are extensively used as feed additives to establish a protective microflora in the gastrointestinal tract of calves. Ruminal microorganisms are composed of many kinds of bacteria, and we hypothesized that compound probiotics could benefit the animals. Thus, we used a com-

Table 6. Effects of compound probiotics on ruminal fermentation parameters of Holstein calves

\begin{tabular}{lccccc}
\hline & \multicolumn{5}{c}{ Diet $^{1}$} \\
\cline { 2 - 4 } Item & CON & LP & HP & SEM & P-value \\
\hline $\mathrm{nyHnnnn} \mathrm{NH}_{3}$-N, mmol/L & 5.89 & 5.70 & 5.84 & 0.071 & 0.548 \\
Total VFA, mmol/L & 3.62 & 4.09 & 3.75 & 0.214 & 0.669 \\
Acetic acid, mmol/L & 100.45 & 88.95 & 82.28 & 3.380 & 0.109 \\
Propionic acid, mmol/L & $46.56^{\mathrm{a}}$ & $36.64^{\mathrm{b}}$ & $35.37^{\mathrm{b}}$ & 1.528 & 0.006 \\
Isobutyric acid, mmol/L & $40.19^{\mathrm{a}}$ & $29.98^{\mathrm{b}}$ & $23.54^{\mathrm{b}}$ & 2.022 & 0.003 \\
Butyric acid, mmol/L & 0.51 & 0.46 & 0.54 & 0.035 & 0.634 \\
Isovaleric acid, mmol/L & $8.00^{\mathrm{b}}$ & $14.57^{\mathrm{a}}$ & $13.93^{\mathrm{a}}$ & 1.000 & 0.016 \\
Valeric acid, mmol/L & 0.60 & 0.43 & 0.59 & 0.056 & 0.379 \\
Acetic:propionic & 4.58 & 6.86 & 8.31 & 0.761 & 0.163 \\
\hline
\end{tabular}

${ }^{\mathrm{a}, \mathrm{b}}$ Mean values in the same row with different superscripts differ $(P<0.05)$.

${ }^{1}$ Diet supplemented with compound probiotics in different levels: $\mathrm{CON}=$ control, both milk replacer and starter pellets supplemented with no compound probiotics; LP = low compound probiotics, milk replacer supplemented with $0.12 \mathrm{~g}$ of compound probiotics per head per day, and starter pellets supplemented with $0.05 \%$ compound probiotics; HP = high compound probiotics, milk replacer supplemented with $1.2 \mathrm{~g}$ of compound probiotics, and starter pellets supplemented with $0.05 \%$ compound probiotics. 
Table 7. Effects of compound probiotics on rumen microbial community of Holstein calves (\% of total bacteria)

\begin{tabular}{lccccc}
\hline & \multicolumn{3}{c}{ Diet $^{1}$} & & \\
\cline { 2 - 4 } Item & CON & LP & HP & \multirow{2}{*}{ SEM } & P-value \\
\hline Fibrobacter succinogenes & 0.68 & 0.82 & 0.50 & 0.220 & 0.865 \\
Butyrivibrio fibrisolvens & 1.59 & 1.58 & 2.54 & 0.880 & 0.782 \\
Streptococcus bovis & 2.98 & 2.24 & 3.29 & 0.469 & 0.686 \\
Prevotella bryantii & 1.95 & 2.40 & 4.16 & 0.665 & 0.396 \\
Ruminobacter amylophilus & 0.70 & 0.43 & 0.10 & 0.149 & 0.293 \\
\hline
\end{tabular}

${ }^{1}$ Diet supplemented with compound probiotics in different levels: $\mathrm{CON}=$ control, both milk replacer and starter pellets supplemented with no compound probiotics; LP = low compound probiotics, milk replacer supplemented with $0.12 \mathrm{~g}$ of compound probiotics per head per day, and starter pellets supplemented with $0.05 \%$ compound probiotics; HP = high compound probiotics, milk replacer supplemented with $1.2 \mathrm{~g}$ of compound probiotics, and starter pellets supplemented with $0.05 \%$ compound probiotics.

mercial compound probiotics product to evaluate its effects on the Holstein calves.

For calves, preweaning and postweaning are 2 crucial stages, during which calves are especially susceptible to intestinal infectious diseases. If calves become ill during the first few weeks of life, growth may decrease and result in death or poor productivity, even into adulthood (Ishihara et al., 2001). In our study, no significant differences were found in BW, DMI, feed efficiency, and ADG. Consistent with our study, Zhang et al. (2016) found that oral supplements of Lactobacillus plantarum and Bacillus subtilis did not affect the DMI and BW of Holstein calves. However, Timmerman et al. (2005) observed that Lactobacillus strains significantly improved ADG and feed efficiency, and Frizzo et al. (2010) also reported that diet supplemented with Lactobacillus casei, Lactobacillus salivarius, and Pediococcus acidilactici promoted earlier consumption of starter and better growth performance. The different results of these studies could be explained by possible factors including the health status, the level of stress suffered by calves, and the exposure to intestinal pathogens during rearing. It has been proven that the beneficial effect due to lactic acid bacteria supplementation can be detected more easily in farms that present high morbidity and mortality rates caused mainly by intestinal pathogens (Signorini et al., 2012). The body size can reflect the growth performance and development, and can also be used to predict the environmental adaptability and potential production performance of cattle (Heinrichs et al., 2007). In the present study, the withers heights of HP and LP calves were lower than those of CON calves at $90 \mathrm{~d}$ of age, whereas Noori et al. (2016) found that probiotics could increase the withers height of Holstein calves. The reason may be that the probiotics yogurt Monzhgan added could have increased mineral bioavailability such as calcium, phosphorus, and magnesium, which are beneficial to the growth of body size. The IGF-1, primarily produced in liver, plays a vital role in growth regulation, development, and metabolism in

Table 8. Effect of compound probiotics on fecal score and medicine treatments of Holstein calves

\begin{tabular}{|c|c|c|c|c|c|c|c|}
\hline Item & \multicolumn{3}{|c|}{$\operatorname{Diet}^{1}$} & SEM & \multicolumn{3}{|c|}{$P$-value } \\
\hline \multicolumn{8}{|l|}{ Fecal score } \\
\hline Week 2 & 2.13 & 2.21 & 2.14 & 0.042 & 0.343 & 0.212 & 0.084 \\
\hline Week 3 & 2.11 & 1.99 & 2.00 & 0.027 & 0.004 & 0.301 & 0.246 \\
\hline Week 4 & 1.99 & 1.99 & 2.00 & 0.007 & 0.606 & 0.545 & 0.379 \\
\hline Diarrhea & 1 & 0 & 2 & & & & \\
\hline Fever & 3 & 0 & 0 & & & & \\
\hline Pneumonia & 7 & 4 & 3 & & & & \\
\hline Cough & 2 & 0 & 0 & & & & \\
\hline Total & 13 & 4 & 5 & & & & \\
\hline
\end{tabular}

${ }^{1}$ Diet supplemented with compound probiotics in different levels: $\mathrm{CON}=$ control, both milk replacer and starter pellets supplemented with no compound probiotics; LP = low compound probiotics, milk replacer supplemented with $0.12 \mathrm{~g}$ of compound probiotics per head per day, and starter pellets supplemented with $0.05 \%$ compound probiotics; HP = high compound probiotics, milk replacer supplemented with $1.2 \mathrm{~g}$ of compound probiotics, and starter pellets supplemented with $0.05 \%$ compound probiotics. 
cattle (Mullen et al., 2011). Consistent with the growth performance, no significant differences were found in IGF-1 concentrations among the groups.

Total protein, including immunoglobulins and nonimmunoglobulin serum proteins, correlates with the immune system of animals (Wang et al., 2020). In young animals, variation in total protein is positively correlated with IgG concentration in the blood (Quigley and Wolfe, 2003). In the present study, although the concentrations of serum total protein of calves in the HP group were higher than those in the CON and LP groups at $40 \mathrm{~d}$ of age, total protein is no longer useful at the age of $40 \mathrm{~d}$ in contrast to in the first days of life. Diet supplemented with high doses of compound probiotics tended to increase the concentrations of immunoglobulins, indicating that oral administration with high doses of compound probiotics may improve the immune systems of calves. Oxidative biomarkers are usually used as indicators of the physiological and health status of an animal (Ranade et al., 2014). Blood MDA, as a product of oxidative stress, is an indicator of lipid peroxidation intensity (Castillo et al., 2006). In the present study, diet supplemented with HP increased the activity of SOD at $80 \mathrm{~d}$ of age, indicating that diet supplemented with HP could improve the antioxidant capacity. The reason may be that the compound probiotic used in our study contained Lactobacillus plantarum, which contains a remarkable level of glutathione, expresses Mn-SOD, degrades hydrogen peroxide, and scavenges reactive oxygen species (Amanatidou et al., 2001; Kullisaar et al., 2002).

The $\mathrm{pH}$ of rumen fluid is an important indicator that reflects the internal environment and health of rumen, as well as the degree of fermentation. In the present study, diet supplemented with compound probiotics had no effects on the $\mathrm{pH}$ of ruminal fluid. Consistent with our results, researchers have reported no variation in rumen fluid $\mathrm{pH}$ when cows are supplied with Bacillus subtilis and Bacillus licheniformis, or provided Lactobacillus plantarum and Bacillus subtilis (Qiao et al., 2010; Zhang et al., 2016). Although rumen fluid pH in our study was lower when compared with the 2 studies above, this could be because calves in this study were provided diet without roughage, and calves fed diets containing 40 to $100 \%$ concentrate have a rumen $\mathrm{pH}$ range of 5.09 to 5.31, with an increasing value with age (Suárez et al., 2007; Khan et al., 2008). We observed that diet supplemented with compound probiotics decreased ruminal acetic acid and propionic acid. The reason may be that the compound probiotics used in the current experiment included $10^{8} \mathrm{cfu} / \mathrm{g}$ of Lactobacillus plantarum and $10^{8} \mathrm{cfu} / \mathrm{g}$ of Pediococcus acidilactici, and it has been proven that when lactic acid bacteria in the rumen reach $10^{6}$ and $10^{7} \mathrm{cfu} / \mathrm{mL}$, the rumen
$\mathrm{pH}$ reduces due to lactic acid fermentation (Nocek et al., 2002). Although the total VFA were similar among the groups, which was different than the report that Lactobacillus plantarum could reduce total VFA (Lettat et al., 2012), the concentrations of total VFA in HP and LP groups were numerically lower than that in CON group. Our results indicated that diet supplemented with compound probiotics promoted the production of butyric acid, which is the main energy resource of the rumen wall, suggesting that the compound probiotics improved the rumen development.

The bacteria Fibrobacter succinogenes, Butyrivibrio fibrisolvens, Streptococcus bovis, Prevotella bryantii, and Ruminobacter amylophilus play vital roles in degrading fiber or starch; therefore, they were selected to further investigate the variation of rumen fermentation (Cotta, 1988; Nagaraja and Titgemeyer, 2007). Streptococcus bovis has been proven to produce mainly lactic acid when $\mathrm{pH}$ is lower than 5.5; however it shifts to formate, acetate, and ethanol fermentation when $\mathrm{pH}$ is higher than 6.0 (Chen et al., 2016). In our study, there was no difference in the abundance of rumen bacteria, but the relative abundances of Streptococcus bovis and Prevotella bryantii of calves in the HP group were numerically higher. Based on our results, the ruminal $\mathrm{pH}$ was among 5.5 to 6.0 , which may partly promote Streptococcus bovis to produce lactate. Chiquette et al. (2008) used Prevotella bryantii as a probiotic in earlylactation dairy cows and found that the bacteria could increase butyrate concentrations in the rumen. In the present study, although the Prevotella bryantii was not significantly higher in the LP and HP groups, the numerically higher abundance of Prevotella bryantii in compound probiotics groups may promote the production of butyric acid and improve the development of rumen.

Diarrhea in preweaning dairy calves is associated with morbidity, malabsorption, and poor production performance later in life (Cho and Yoon, 2014). In the present study, calves partly suffered from diseases including diarrhea, fever, pneumonia, or cough. Diarrhea is strongly related to inflammation of the gastrointestinal tract and further affects growth performance of calves (Klein et al., 2008; Bateman et al., 2012). Acute diarrhea is the primary issue for the first $3 \mathrm{wk}$ of life and is replaced by respiratory disease by around $4 \mathrm{wk}$ of age (Björkman et al., 2003; Murray et al., 2018). The fecal score system is commonly used for predicting diarrhea in young animals (Renaud et al., 2020). Interestingly, at the first $2 \mathrm{wk}$ of age, the diarrhea did not differ among the groups, whereas calves fed with the HP and LP diets decreased diarrhea at the third week of age. The reason may be that in this study, although both milk replacer (from $1 \mathrm{~d}$ of age) and starter pellets 
(from $7 \mathrm{~d}$ of age) were added the compound probiotics, it has been proven that substantial development of the forestomach is generally considered obtained within the first 3 to 4 wk of postnatal life (Górka et al., 2018). After, the rumen and the microbiomes develop, which provides an environment for the compound probiotics to colonize and turnback to affect hold animals. In the present study, the fecal score was affected by the age of calves during the first 4 wk of age, which is consistent with the report that acute diarrhea is the primary issue for the first 3 wk of life and replaced by respiratory disease by around 4 wk of age (Murray et al., 2018). In one study, diarrhea varied from $16 \%$ to $27 \%$ when calves were born during different seasons, with an average percent of $23 \%$; within-herd prevalence had higher diarrhea rates than within-pen prevalence, where the average diarrhea was $23.75 \%$ and $17.75 \%$, respectively (Medrano-Galarza et al., 2018). In the present study, the diarrhea of calves was at an average of $5.95 \%$, which was generally lower than that in other studies, suggesting the environment and management of the experimental farms were in very good condition. We speculated that the improvement effect of compound probiotics will be greater in farms with poor environmental and management conditions. Consistent with the result of diarrhea, the medicine treatments were less in the LP and HP groups compared those in the CON group.

\section{CONCLUSIONS}

Diet supplemented with compound probiotics had no effects on growth performance, although it decreased the withers height at the age of $90 \mathrm{~d}$. Diet supplemented with HP showed potential improvement of calf immunity, indicated by increased concentrations of serum total protein and immunoglobulins at $40 \mathrm{~d}$ of age, and antioxidant capacity, indicated by increased activity of SOD at $80 \mathrm{~d}$ of age. Diet supplemented with compound probiotics altered rumen fermentation and improved rumen development, indicated by ruminal fermentation parameters. Diet supplemented with compound probiotics improved health of calves, indicated by decreasing fecal score and medicine treatments. Hence, the high dosage of compound probiotics is recommended to improve the rumen development and health status of newborn Holstein calves

\section{ACKNOWLEDGMENTS}

The authors give special thanks to the Modern Farming (Bengbu, Anhui province, China) for the assistance for animal care and sample collection. This research was funded by the China Agriculture Research System
(CARS-37; Beijing, China) and BioWish Technologies (Cincinnati, OH). The authors have not stated any conflicts of interest.

\section{REFERENCES}

Alawneh, J. I., M. O. Barreto, R. J. Moore, M. Soust, H. Al-Harbi, A. S. James, D. Krishnan, and T. W. J. Olchowy. 2020. Systematic review of an intervention: The use of probiotics to improve health and productivity of calves. Prev. Vet. Med. 183:105147. https:// doi.org/10.1016/j.prevetmed.2020.105147.

Amanatidou, A., E. J. Smid, M. H. Bennik, and L. G. Gorris. 2001. Antioxidative properties of Lactobacillus sake upon exposure to elevated oxygen concentrations. FEMS Microbiol. Lett. 203:87-94. https://doi.org/10.1111/j.1574-6968.2001.tb10825.x.

AOAC. 1990. Official methods of analysis: 15 th edition.

Bateman, H. G. II, T. M. Hill, J. M. Aldrich, R. L. Schlotterbeck, and J. L. Firkins. 2012. Meta-analysis of the effect of initial serum protein concentration and empirical prediction model for growth of neonatal Holstein calves through 8 weeks of age. J. Dairy Sci. 95:363-369. https://doi.org/10.3168/jds.2011-4594.

Björkman, C., C. Svensson, B. Christensson, and K. de Verdier. 2003. Cryptosporidium parvum and Giardia intestinalis in calf diarrhoea in Sweden. Acta Vet. Scand. 44:145-152. https://doi.org/10.1186/ 1751-0147-44-145.

Castillo, C., J. Hernandez, I. Valverde, V. Pereira, J. Sotillo, M. L. Alonso, and J. L. Benedito. 2006. Plasma malonaldehyde (MDA) and total antioxidant status (TAS) during lactation in dairy cows. Res. Vet. Sci. 80:133-139. https://doi.org/10.1016/j.rvsc.2005.06 .003 .

Chen, L., S. Liu, H. Wang, M. Wang, and L. Yu. 2016. Relative significances of $\mathrm{pH}$ and substrate starch level to roles of Streptococcus bovis $\mathrm{S} 1$ in rumen acidosis. AMB Express 6:80. https://doi.org/10 .1186/s13568-016-0248-2.

Chiquette, J., M. J. Allison, and M. A. Rasmussen. 2008. Prevotella bryantii 25A used as a probiotic in early-lactation dairy cows: Effect on ruminal fermentation characteristics, milk production, and milk composition. J. Dairy Sci. 91:3536-3543. https://doi.org/10 .3168/jds.2007-0849.

Cho, Y. I., and K. J. Yoon. 2014. An overview of calf diarrhea - Infectious etiology, diagnosis, and intervention. J. Vet. Sci. 15:1-17. https://doi.org/10.4142/jvs.2014.15.1.1.

Cotta, M. A. 1988. Amylolytic activity of selected species of ruminal bacteria. Appl. Environ. Microbiol. 54:772-776. https://doi.org/10 .1128/aem.54.3.772-776.1988.

Denman, S. E., and C. S. McSweeney. 2006. Development of a realtime PCR assay for monitoring anaerobic fungal and cellulolytic bacterial populations within the rumen. FEMS Microbiol. Ecol. 58:572-582. https://doi.org/10.1111/j.1574-6941.2006.00190.x.

Diao, Q., R. Zhang, and T. Fu. 2019. Review of strategies to promote rumen development in calves. Animals (Basel) 9:490. https://doi .org/10.3390/ani9080490.

Frizzo, L., L. P. Soto, M. V. Zbrun, E. Bertozzi, G. Sequeira, R. R. Armesto, and M. R. Rosmini. 2010. Lactic acid bacteria to improve growth performance in young calves fed milk replacer and spray-dried whey powder. Anim. Feed Sci. Technol. 157:159-167. https://doi.org/10.1016/j.anifeedsci.2010.03.005.

Garcia-Mazcorro, J. F., S. L. Ishaq, M. V. Rodriguez-Herrera, C. A. Garcia-Hernandez, J. R. Kawas, and T. G. Nagaraja. 2020. Review: Are there indigenous Saccharomyces in the digestive tract of livestock animal species? Implications for health, nutrition and productivity traits. Animal 14:22-30. https://doi.org/10.1017/ S1751731119001599.

Górka, P., Z. M. Kowalski, R. Zabielski, and P. Guilloteau. 2018. Invited review: Use of butyrate to promote gastrointestinal tract development in calves. J. Dairy Sci. 101:4785-4800. https://doi .org/10.3168/jds.2017-14086.

Hammon, H. M., W. Liermann, D. Frieten, and C. Koch. 2020. Review: Importance of colostrum supply and milk feeding intensity 
on gastrointestinal and systemic development in calves. Animal 14(S1):s133-s143. https://doi.org/10.1017/S1751731119003148.

Heinrichs, A. J., H. N. Erb, G. W. Rogers, J. B. Cooper, and C. M. Jones. 2007. Variability in Holstein heifer heart-girth measurements and comparison of prediction equations for live weight. Prev. Vet. Med. 78:333-338. https://doi.org/10.1016/j.prevetmed .2006.11.002.

Hill, C., F. Guarner, G. Reid, G. R. Gibson, D. J. Merenstein, B. Pot, L. Morelli, R. B. Canani, H. J. Flint, S. Salminen, P. C. Calder, and M. E. Sanders. 2014. Expert consensus document. The International Scientific Association for Probiotics and Prebiotics consensus statement on the scope and appropriate use of the term probiotic. Nat. Rev. Gastroenterol. Hepatol. 11:506-514. https:// doi.org/10.1038/nrgastro.2014.66.

Ishihara, N., D.-C. Chu, S. Akachi, and L. Juneja. 2001. Improvement of intestinal microflora balance and prevention of digestive and respiratory organ diseases in calves by green tea extracts. Livest. Prod. Sci. 68:217-229. https://doi.org/10.1016/S0301 -6226(00)00233-5.

Khan, M. A., H. J. Lee, W. S. Lee, H. S. Kim, S. B. Kim, S. B. Park, K. S. Baek, J. K. Ha, and Y. J. Choi. 2008. Starch source evaluation in calf starter: II. Ruminal parameters, rumen development, nutrient digestibilities, and nitrogen utilization in Holstein calves. J. Dairy Sci. 91:1140-1149. https://doi.org/10.3168/jds.2007-0337.

Klein, P., T. Kleinová, Z. Volek, and J. Simůnek. 2008. Effect of Cryptosporidium parvum infection on the absorptive capacity and paracellular permeability of the small intestine in neonatal calves. Vet. Parasitol. 152:53-59. https://doi.org/10.1016/j.vetpar.2007 .11 .020 .

Kullisaar, T., M. Zilmer, M. Mikelsaar, T. Vihalemm, H. Annuk, C. Kairane, and A. Kilk. 2002. Two antioxidative lactobacilli strains as promising probiotics. Int. J. Food Microbiol. 72:215-224. https: //doi.org/10.1016/S0168-1605(01)00674-2.

Lettat, A., P. Nozière, M. Silberberg, D. P. Morgavi, C. Berger, and C. Martin. 2012. Rumen microbial and fermentation characteristics are affected differently by bacterial probiotic supplementation during induced lactic and subacute acidosis in sheep. BMC Microbiol. 12:142. https://doi.org/10.1186/1471-2180-12-142.

Livak, K. J., and T. D. Schmittgen. 2001. Analysis of relative gene expression data using real-time quantitative PCR and the 2(-Delta Delta C(T)). Methods 25:402-408. https://doi.org/10.1006/meth .2001 .1262

Malmuthuge, N., P. J. Griebel, and L. L. Guan. 2015. The gut microbiome and its potential role in the development and function of newborn calf gastrointestinal tract. Front. Vet. Sci. 2:36. https:// doi.org/10.3389/fvets.2015.00036.

Medrano-Galarza, C., S. J. LeBlanc, A. Jones-Bitton, T. J. DeVries, J. Rushen, A. Marie de Passille, M. I. Endres, and D. B. Haley. 2018. Associations between management practices and within-pen prevalence of calf diarrhea and respiratory disease on dairy farms using automated milk feeders. J. Dairy Sci. 101:2293-2308. https: //doi.org/10.3168/jds.2017-13733.

Meganck, V., G. Hoflack, S. Piepers, and G. Opsomer. 2015. Evaluation of a protocol to reduce the incidence of neonatal calf diarrhoea on dairy herds. Prev. Vet. Med. 118:64-70. https://doi.org/ 10.1016/j.prevetmed.2014.11.007.

Mullen, M. P., D. P. Berry, D. J. Howard, M. G. Diskin, C. O. Lynch, L. Giblin, D. A. Kenny, D. A. Magee, K. G. Meade, and S. M. Waters. 2011. Single nucleotide polymorphisms in the insulin-like growth factor 1 (IGF-1) gene are associated with performance in Holstein-Friesian dairy cattle. Front. Genet. 2:3. https://doi.org/ 10.3389/fgene.2011.00003.

Murray, G. M., S. J. More, T. A. Clegg, B. Earley, R. G. O'Neill, D. Johnston, J. Gilmore, M. Nosov, M. C. McElroy, T. J. Inzana, and J. P. Cassidy. 2018. Risk factors associated with exposure to bovine respiratory disease pathogens during the peri-weaning period in dairy bull calves. BMC Vet. Res. 14:53. https://doi.org/ 10.1186/s12917-018-1372-9.

Nagaraja, T. G., and E. Titgemeyer. 2007. Ruminal acidosis in beef cattle: The current microbiological and nutritional outlook. J. Dairy Sci. 90:E17-E38. https://doi.org/10.3168/jds.2006-478.
Niu, W., Y. He, H. Wang, C. Xia, H. Shi, B. Cao, and H. Su. 2018. Effects of Leymus chinensis replacement with whole-crop wheat hay on blood parameters, fatty acid composition, and microbiomes of Holstein bulls. J. Dairy Sci. 101:246-256. https://doi.org/10.3168/ jds.2017-13267.

Nocek, J. E., W. P. Kautz, J. A. Leedle, and J. G. Allman. 2002. Ruminal supplementation of direct-fed microbials on diurnal $\mathrm{pH}$ variation and in situ digestion in dairy cattle. J. Dairy Sci. 85:429-433. https://doi.org/10.3168/jds.S0022-0302(02)74091-5.

Noori, M., M. Alikhani, and R. Jahanian. 2016. Effect of partial substitution of milk with probiotic yogurt of different $\mathrm{pH}$ on performance, body conformation and blood biochemical parameters of Holstein calves. J. Appl. Anim. Res. 44:221-229. https://doi.org/ 10.1080/09712119.2015.1031772.

O'Hara, E., A. L. A. Neves, Y. Song, and L. L. Guan. 2020. The role of the gut microbiome in cattle production and health: driver or passenger? Annu. Rev. Anim. Biosci. 8:199-220. https://doi.org/ 10.1146/annurev-animal-021419-083952.

Osorio, J. S. 2020. Gut health, stress, and immunity in neonatal dairy calves: the host side of host-pathogen interactions. J. Anim. Sci. Biotechnol. 11:105. https://doi.org/10.1186/s40104-020-00509-3.

Osorio, J. S., R. L. Wallace, D. J. Tomlinson, T. J. Earleywine, M. T. Socha, and J. K. Drackley. 2012. Effects of source of trace minerals and plane of nutrition on growth and health of transported neonatal dairy calves. J. Dairy Sci. 95:5831-5844. https://doi.org/ $10.3168 /$ jds.2011-5042

Piewngam, P., Y. Zheng, T. H. Nguyen, S. W. Dickey, H. S. Joo, A E. Villaruz, K. A. Glose, E. L. Fisher, R. L. Hunt, B. Li, J. Chiou, S. Pharkjaksu, S. Khongthong, G. Y. C. Cheung, P. Kiratisin, and M. Otto. 2018. Pathogen elimination by probiotic Bacillus via signalling interference. Nature 562:532-537. https://doi.org/10.1038/ s41586-018-0616-y

Qiao, G. H., A. S. Shan, N. Ma, Q. Q. Ma, and Z. W. Sun. 2010. Effect of supplemental Bacillus cultures on rumen fermentation and milk yield in Chinese Holstein cows. J. Anim. Physiol. Anim. Nutr. (Berl.) 94:429-436. https://doi.org/10.1111/j.1439-0396 .2009.00926.x.

Quigley, J. D. III, and T. M. Wolfe. 2003. Effects of spray-dried animal plasma in calf milk replacer on health and growth of dairy calves. J. Dairy Sci. 86:586-592. https://doi.org/10.3168/jds .S0022-0302(03)73637-6.

Ranade, R., S. Talukder, G. Muscatello, and P. Celi. 2014. Assessment of oxidative stress biomarkers in exhaled breath condensate and blood of dairy heifer calves from birth to weaning. Vet. J. 202:583-587. https://doi.org/10.1016/j.tvil.2014.10.025.

Renaud, D. L., L. Buss, J. N. Wilms, and M. A. Steele. 2020. Technical note: Is fecal consistency scoring an accurate measure of fecal dry matter in dairy calves? J. Dairy Sci. 103:10709-10714. https://doi .org/10.3168/jds.2020-18907.

Signorini, M. L., L. P. Soto, M. V. Zbrun, G. J. Sequeira, M. R. Rosmini, and L. S. Frizzo. 2012. Impact of probiotic administration on the health and fecal microbiota of young calves: A meta-analysis of randomized controlled trials of lactic acid bacteria. Res. Vet. Sci. 93:250-258. https://doi.org/10.1016/j.rvsc.2011.05.001.

Soberon, F., E. Raffrenato, R. W. Everett, and M. E. Van Amburgh. 2012. Preweaning milk replacer intake and effects on long-term productivity of dairy calves. J. Dairy Sci. 95:783-793. https://doi .org/10.3168/jds.2011-4391.

Soberon, F., and M. E. Van Amburgh. 2013. Lactation Biology Symposium: The effect of nutrient intake from milk or milk replacer of preweaned dairy calves on lactation milk yield as adults: a meta-analysis of current data. J. Anim. Sci. 91:706-712. https://doi .org/10.2527/jas.2012-5834.

Stevenson, D. M., and P. J. Weimer. 2007. Dominance of Prevotella and low abundance of classical ruminal bacterial species in the bovine rumen revealed by relative quantification real-time PCR. Appl. Microbiol. Biotechnol. 75:165-174. https://doi.org/10.1007/ s00253-006-0802-y.

Suárez, B. J., C. G. Van Reenen, N. Stockhofe, J. Dijkstra, and W. J. Gerrits. 2007. Effect of roughage source and roughage to concentrate ratio on animal performance and rumen development in 
veal calves. J. Dairy Sci. 90:2390-2403. https://doi.org/10.3168/ jds.2006-524.

Tang, K. L., N. P. Caffrey, D. B. Nóbrega, S. C. Cork, P. E. Ronksley, H. W. Barkema, A. J. Polachek, H. Ganshorn, N. Sharma, J. D. Kellner, and W. A. Ghali. 2017. Restricting the use of antibiotics in food-producing animals and its associations with antibiotic resistance in food-producing animals and human beings: a systematic review and meta-analysis. Lancet Planet. Health 1:e316-e327. https://doi.org/10.1016/S2542-5196(17)30141-9.

Timmerman, H. M., L. Mulder, H. Everts, D. C. van Espen, E. van der Wal, G. Klaassen, S. M. Rouwers, R. Hartemink, F. M. Rombouts, and A. C. Beynen. 2005. Health and growth of veal calves fed milk replacers with or without probiotics. J. Dairy Sci. 88:2154-2165. https://doi.org/10.3168/jds.S0022-0302(05)72891-5.

Walter, J., M. X. Maldonado-Gomez, and I. Martinez. 2018. To engraft or not to engraft: an ecological framework for gut microbiome modulation with live microbes. Curr. Opin. Biotechnol. 49:129 139. https://doi.org/10.1016/j.copbio.2017.08.008.

Wang, H., F. Wu, T. Guan, Y. Zhu, Z. Yu, D. Zhang, S. Zhang, H. $\mathrm{Su}$, and B. Cao. 2020. Chopping roughage length improved rumen development of weaned calves as revealed by rumen fermentation and bacterial community. Animals (Basel) 10:2149. https://doi .org/10.3390/ani10112149.
Weatherburn, M. 1967. Phenol-hypochlorite reaction for determination of ammonia. Anal. Chem. 39:971-974. https://doi.org/10 .1021/ac60252a045.

Williams, P. 2007. Bacillus subtilis: A shocking message from a probiotic. Cell Host Microbe 1:248-249. https://doi.org/10.1016/j.chom 2007.05.010.

Wilson, L. L., C. L. Egan, and T. L. Terosky. 1997. Body measurements and body weights of special-fed Holstein veal calves. J. Dairy Sci. 80:3077-3082. https://doi.org/10.3168/jds.S0022 $-0302(97) 76277-5$.

Zhang, R., M. Zhou, Y. Tu, N. F. Zhang, K. D. Deng, T. Ma, and Q. Y. Diao. 2016. Effect of oral administration of probiotics on growth performance, apparent nutrient digestibility and stress-related indicators in Holstein calves. J. Anim. Physiol. Anim. Nutr. (Berl.) 100:33-38. https://doi.org/10.1111/jpn.12338.

\section{ORCIDS}

Haibo Wang 우 https://orcid.org/0000-0002-6950-5117 Huawei Su $\odot$ https://orcid.org/0000-0001-9934-9576 